\title{
The cost-effectiveness of the WINGS intervention: a program to prevent HIV and sexually transmitted diseases among high-risk
} urban women

\author{
Harrell W Chesson*1, Judith B Greenberg ${ }^{1}$ and Michael Hennessy ${ }^{2}$
}

Address: ${ }^{1}$ Division of STD Prevention, Centers for Disease Control and Prevention, Atlanta, Georgia, USA and ${ }^{2}$ Annenberg School for Communication, University of Pennsylvania, Philadelphia, Pennsylvania, USA

E-mail: Harrell W Chesson* - hbc7@cdc.gov; Judith B Greenberg - jgreenb@bellsouth.net; Michael Hennessy - mhennessy@asc.upenn.edu

${ }^{*}$ Corresponding author

Published: II October 2002

BMC Infectious Diseases 2002, 2:24

This article is available from: http://www.biomedcentral.com/I47/-2334/2/24

This article is published in Open Access: verbatim copying and redistribution of this article are permitted in all media for any purpose, provided this notice is preserved along with the article's original URL.
Received: 15 May 2002

Accepted: II October 2002

\begin{abstract}
Background: We evaluated the cost-effectiveness of the WINGS project, an intervention to prevent HIV and other sexually transmitted diseases among urban women at high risk for sexual acquisition of HIV.

Methods: We used standard methods of cost-effectiveness analysis. We conducted a retrospective analysis of the intervention's cost and we used a simplified model of HIV transmission to estimate the number of HIV infections averted by the intervention. We calculated costeffectiveness ratios for the complete intervention and for the condom use skills component of the intervention.

Results: Under base case assumptions, the intervention prevented an estimated 0.2195 new cases of HIV at a cost of $\$ 215,690$ per case of HIV averted. When indirect costs of HIV were excluded from the analysis, the intervention's cost-effectiveness ratios were $\$ 357,690$ per case of HIV averted and $\$ 31,85 \mathrm{I}$ per quality-adjusted life year (QALY) saved. Under base case assumptions, the condom use skills component of the intervention prevented an estimated $0.1756 \mathrm{HIV}$ infections and was cost-saving. When indirect HIV costs were excluded, the cost-effectiveness ratios for the condom use skills component of the intervention were $\$ 97,404$ per case of HIV averted and $\$ 8,674$ per QALY saved.
\end{abstract}

Conclusions: The WINGS intervention, particularly the two sessions of the intervention which focussed on condom use skills, could be cost-effective in preventing HIV among women.

\section{Background}

HIV infection among women in the United States has increased significantly over the last fifteen years, and recent estimates suggest that as many as 160,000 adult and adolescent women are living with HIV infection and/or AIDS [1]. Women accounted for almost one fourth of the new
AIDS cases reported in 1999, and most of these women were infected with HIV through heterosexual contact.

HIV prevention interventions can reduce risky sexual behaviour of women [2], and numerous studies have documented the effectiveness of various cognitive-behavioural 
Table I: WINGS intervention content

\begin{tabular}{|c|c|c|c|}
\hline Session title & General education activities & Condom skills activities & Communication skills activities \\
\hline I. Getting and staying healthy & $\begin{array}{l}\text { Identifying women's health con- } \\
\text { cerns and community resources } \\
\text { for women's health }\end{array}$ & None & $\begin{array}{l}\text { Introduction to basic elements of } \\
\text { communication; role plays }\end{array}$ \\
\hline 2. Straight talk & Female anatomy & None & Barriers to communication; role plays \\
\hline 3. Sexually transmitted diseases and HIV & $\begin{array}{l}\text { Disease information, including } \\
\text { long-term consequences of } \\
\text { STDs in women }\end{array}$ & $\begin{array}{l}\text { Male condom demonstration } \\
\text { and practice; ways to make } \\
\text { condom use fun }\end{array}$ & $\begin{array}{l}\text { Ways to introduce condoms to resist- } \\
\text { ant partners }\end{array}$ \\
\hline 4. Choosing safer sex & $\begin{array}{l}\text { Contraceptive choices and risk } \\
\text { reduction }\end{array}$ & $\begin{array}{l}\text { Skill practice in using the } \\
\text { female condom }\end{array}$ & Role plays for implementing safer sex \\
\hline $\begin{array}{l}\text { 5. Living dangerously: sex, drugs, and } \\
\text { HIV }\end{array}$ & $\begin{array}{l}\text { Drug use and abuse; signs of } \\
\text { addiction; treatment resources; } \\
\text { harm reduction }\end{array}$ & None & $\begin{array}{l}\text { "Keeping safe" role plays for risky situ- } \\
\text { ations related to drug and alcohol use }\end{array}$ \\
\hline 6. Relationships & $\begin{array}{l}\text { Discussion of risky relationships; } \\
\text { resources for help and safety } \\
\text { issues such as shelter programs }\end{array}$ & None & None \\
\hline
\end{tabular}

group intervention models [3-10]. For example, persons who participated in a 30-minute condom use skills educational session in a Los Angeles waiting room were less likely to return to the sexually transmitted disease (STD) clinic with a new STD than those who did not participate in the educational session [11].

Many interventions have been successful in increasing condom usage by supplementing condom use education and/or general HIV/AIDS education with training in other areas, such as negotiation skills (how to suggest condom use with a new partner), assertiveness skills (how to resist unwanted sexual advances) and cognitive coping skills (such as sexual self-control) and by improving self-esteem $[4-6,9,12]$. Policy- and decision-makers who plan HIV prevention programs need information about the cost-effectiveness of these programs in order to maximize the benefits of limited HIV prevention resources $[7,13]$.

Here, we evaluated the cost-effectiveness of the Women in Group Support (WINGS) project, a six-session groupbased intervention that offered training in condom use skills (using condoms correctly) and in communication skills (such as talking to sex partners about condom usage) for urban heterosexual women at high risk of acquiring HIV and other STDs.

\section{Methods}

\section{Intervention content, delivery, and efficacy}

The methods of the WINGS intervention trial have been described previously $[10,14,15]$. A total of 604 HIV-uninfected women at high risk for STD/HIV were recruited from Baltimore, New York, and Seattle from May 1995 through July 1997. After completing baseline interviews, the women were randomly assigned to the intervention or to the control group. The intervention group sessions included components on reducing HIV and STD risk identified by Fisher and Fisher [16], specifically training in the proper use of male and female condoms and building skills in communication to sex partners to encourage condom use (Table 1). Participants in the control group attended a 1-hour session on nutrition.

Condom usage by the women in the WINGS intervention increased substantially, and at least part of this increase was attributable to intervention's effect on condom use skills and communication skills $[10,15]$. A model-based evaluation of the efficacy of the WINGS intervention [10] demonstrated that most of the intervention's effect on increasing condom usage was attributable to the condom use skills component of the intervention.

This analysis focussed on the cost-effectiveness of the intervention. We evaluated the cost-effectiveness of the complete six-session intervention and the two sessions of the intervention that addressed condom use skills. For brevity, we refer to the complete, six-session WINGS intervention as the "complete intervention" and we refer to the two sessions that addressed condom skills training as the "condom use skills component" of the intervention. The condom use skills component was part of (not an alternative to) the complete intervention. To evaluate the cost-effectiveness of the condom use skills component of the intervention, we estimated the increase in condom usage attributable to the condom use skills component.

We examined cost-effectiveness from the societal perspective, in which relevant costs and benefits were included in 
the analysis without regard to who might actually pay the costs or receive the benefits [17]. We calculated intervention costs for the period during which the intervention was delivered. Benefits of the intervention (averted HIV infections) were assumed to accrue in the 6 months following the intervention. The societal cost per HIV infection included the future medical care costs and indirect costs such as lost productivity, discounted at 3\% annually.

The cost-effectiveness analysis comprised four main steps: (1) retrospective analysis of the intervention's cost, (2) estimation of the number of HIV infections averted by the intervention, (3) calculation of the cost-effectiveness ratios, and (4) sensitivity analyses to examine how the costeffectiveness ratios would change over a range of assumptions about cost and effectiveness. We present the methods to evaluate the cost-effectiveness of the complete intervention. Except where noted, the methods to evaluate the "condom use skills component" were identical.

\section{Estimating the intervention's cost}

Cost estimates (in 1996 dollars) were based primarily on cost information provided by the WINGS principal investigators, who estimated the various resources required to deliver the intervention. We obtained additional information from budget proposals of the WINGS project and from cost estimates of an earlier intervention of similar duration and intensity [13]. Because women attended sessions in small groups, costs were calculated per group of six women. Our assessment of intervention costs included the cost of rent for participant meeting spaces (including overhead and miscellaneous costs), facilitator wages and training, senior staff time for quality assurance, recruitment, client costs (incentive payments, child care and transportation compensation, and meals), and materials (such as condoms, anatomic models, and information pamphlets).

The child care compensation, travel compensation, and incentive payments were assumed to cover all costs (direct and indirect) borne by the participants, such as travel expenses and foregone time for work or leisure. In calculating recruitment costs, we assumed that $75 \%$ of the total recruitment costs could be attributed to the randomized control nature of the study and not to the intervention itself.

In assessing the cost of the condom use skills component of the intervention, we divided each cost item included in the complete intervention (except recruitment and materials) by three, as the condom use skills component had one-third the number of sessions as the complete intervention. Recruitment and materials costs in the condom use skills component were assumed to be the same as the complete intervention, since recruitment would still be necessary regardless of the duration of the intervention and since most of the materials cost in the complete intervention were attributable to the two sessions of the intervention focussing on condom use skills.

\section{HIV cases averted}

The number of HIV infections averted (A) by the intervention was estimated according to Equation 1:

$A=R\left[1-\frac{\left(1-\varepsilon \rho_{i}\right)}{\left(1-\varepsilon \rho_{b}\right)}\right] N$

where the intervention is assumed to increase the percentage of sexual encounters protected by condoms from $\rho_{b}$ to $\rho_{\mathrm{i}}, \in$ is condom effectiveness per act of intercourse, $\mathrm{R}$ is the probability of acquiring HIV in the absence of the intervention, and $\mathrm{N}$ is the number of women in the intervention.

This approximation is derived from a model-based evaluation of the benefits of increases in occasional condom usage, which suggested that under conditions that prevail in many at-risk heterosexual populations the relationship between increased condom usage and HIV risk reduction is essentially linear [18]. For example, if condoms were 95\% effective in preventing HIV transmission, then an increase in condom usage from $0 \%$ to $100 \%$ would reduce the risk of acquiring HIV by about 95\%. Smaller increases in condom usage would yield smaller reductions in risk.

Parameter values for equation 1 are summarized in Table 2. Values for $\rho_{b}$ and $\rho_{i}$ were obtained from the structural equation model estimates in a previous study of the efficacy of the WINGS intervention [10]. Based on these model estimates (see appendix), we applied the following base case values for condom usage following the intervention: $53.2 \%$ for the control group, $57.7 \%$ for the complete intervention, and $56.8 \%$ for the condom use skills component.

Based on data from several sources, we assumed 0.019 as the base case annual probability of acquiring HIV in the absence of the intervention. Recent studies of high-risk urban women from several cities in the United States suggest HIV incidence rates in the range of 0.018 to more than 7 new infections per 100 person-years [19-24], with the highest rates observed among women who reported exchanging sex for money or drugs and women with a recent history of acquiring other STDs such as syphilis. Of the women initially recruited for the WINGS trial, about onefourth reported trading sex for money or drugs and almost one-third reported having an STD in the previous year [14]. 
Table 2: Behavioural, epidemiological, and cost parameters: Base case values and ranges

\begin{tabular}{|c|c|c|c|}
\hline Parameter & Base case value & Range & Source \\
\hline Condom use, without participation in intervention $\left(\rho_{b}\right)$ & $53.2 \%$ & - & $\begin{array}{l}\text { Greenberg et al [10], as } \\
\text { described in appendix }\end{array}$ \\
\hline Condom use, with participation in full intervention $\left(\rho_{\mathrm{i}}\right)$ & $57.7 \%$ & $55.45 \%-59.95 \%$ & $\begin{array}{l}\text { Greenberg et al [10], as } \\
\text { described in appendix }\end{array}$ \\
\hline $\begin{array}{l}\text { Condom use, with participation in condom use skills } \\
\text { component of intervention }\left(\rho_{\mathrm{i}}\right)\end{array}$ & $56.8 \%$ & $55 \%-58.6 \%$ & $\begin{array}{l}\text { Greenberg et al [10], as } \\
\text { described in appendix }\end{array}$ \\
\hline $\begin{array}{l}\text { Annual probability of HIV infection without participation } \\
\text { in intervention }(\mathrm{P})\end{array}$ & 0.019 & $0.0095-0.029$ & Various (see text) \\
\hline Condom effectiveness $(\in)$ & $95 \%$ & $85 \%-98 \%$ & Pinkerton and Abramson [25] \\
\hline Number of women in intervention $(\mathrm{N})$ & 266 & - & Greenberg et al (2000) [10] \\
\hline Duration of intervention effect in months (D) & 6 & $3-9$ & Greenberg et al (2000) [10] \\
\hline $\begin{array}{l}\text { Societal cost per case of HIV (includes direct medical } \\
\text { care costs, lost economic productivity and other indirect } \\
\text { costs) }\end{array}$ & $\$ 337,000$ & $\$ 169,000-\$ 506,000$ & $\begin{array}{l}\text { Holtgrave and Pinkerton [27] } \\
\text { and Mullins et al [28], as } \\
\text { described in text }\end{array}$ \\
\hline Direct medical care costs per case of HIV & $\$ 195,000$ & $\$ 98,000-\$ 293,000$ & Holtgrave and Pinkerton [27] \\
\hline Number of QALYs saved per HIV infection averted & 11.23 & $9.34-13.18$ & Holtgrave and Pinkerton [27] \\
\hline
\end{tabular}

Note: Costs are expressed in 1996 US\$.

Condom effectiveness $(\epsilon)$, the reduction in the per-act probability of HIV transmission when a condom is used, was set to $95 \%$ [25]. We assumed the increase in condom usage attributable to the intervention would last 6 months (range: 3 to 9) as the increases in condom usage attributable to the intervention were found to diminish by the sixmonth follow-up interviews [10].

The value of $\mathrm{R}$ was calculated from the annual probability of HIV infection $(\mathrm{P})$ and the assumed duration of the intervention in months (D) as follows: $\mathrm{R}=1-(1-\mathrm{P})^{\mathrm{D} / 12}$. Thus $\mathrm{R}$ represents the base case probability of acquiring HIV (in the absence of the intervention) during the $\mathrm{D}$ months following the intervention.

\section{Cost-effectiveness ratios}

Using standard methods of cost-effectiveness analysis, we calculated the average cost per HIV case averted as the net cost of the intervention divided by the estimated number of HIV infections averted, where net cost refers to the intervention's cost minus the societal costs of HIV averted by the intervention [26]. Averted HIV costs were calculated by multiplying the estimated number of averted HIV cases by the cost per case of HIV.

Our baseline estimate of the societal cost of HIV was $\$ 337,000$ per case, which includes the lifetime medical care costs $(\$ 195,000$, with future costs discounted at 3\% annually) and indirect costs $(\$ 142,000)$ such as lost economic productivity $[27,28]$. This estimate of the indirect costs per case of HIV was based on a recent report that indirect costs of HIV in England comprised between $45 \%$ to
$102 \%$ of the direct treatment costs of HIV [28]. We used the midpoint of this range and assumed that indirect costs would be $73 \%$ of the direct medical costs $(\$ 195,000 \times$ $73 \%=\$ 142,000)$. This estimate of the indirect costs is quite conservative compared to other studies which suggest the indirect costs of HIV exceed the direct medical care costs $[29,30]$.

We did not calculate the cost per quality-adjusted life year (QALY) gained when indirect costs of HIV were included in the cost per case of HIV, because these indirect costs might be "double counted" if included in the numerator (as averted HIV costs) and the denominator (as part of the QALY measure) [31,32]. For completeness, we repeated the analysis excluding the indirect costs of HIV from the numerator, focussing solely on the direct medical care costs $(\$ 195,000)$. The cost per QALY saved was calculated as the net cost of the intervention (the intervention's cost minus the direct medical care costs of HIV averted) divided by the number of QALYs saved. The number of QALYs saved was calculated by multiplying the estimated number of averted HIV cases by published estimates of the number of QALYs saved per HIV case averted [27].

To assess the cost-effectiveness of the complete intervention and the condom use skills component, we compared these interventions to the alternative of no intervention, which we assumed would have $\$ 0$ in program cost and would not avert any new cases of HIV. For the complete intervention, we also calculated the incremental cost-effectiveness ratios, which compare the complete intervention to the condom use skills component. The 
incremental cost per case averted was calculated as difference in net cost (the net cost of the complete intervention minus that of the condom use skills component) divided by the difference in HIV cases averted (HIV cases averted by the complete intervention minus the HIV cases averted by the condom use skills component) [26]. The incremental cost per QALY saved was calculated in an analogous manner.

\section{Sensitivity analyses}

We conducted univariate and multivariate sensitivity analyses. In the univariate analysis, we examined how the estimated cost per case averted changed when we varied one parameter at a time, holding other parameters at their base case values. The parameters we varied were the cost of the intervention, the effectiveness of the intervention (as measured by condom usage after the intervention), condom efficacy, the annual probability of acquiring HIV, the duration of the effectiveness of the intervention, and the cost per case of HIV.

In the multivariate analysis we varied all of the parameters listed above simultaneously. Specifically, we chose values for each parameter under the assumption that these values were uniformly distributed between their respective lower and upper bounds. We then estimated the cost per case averted using these random values. We repeated this procedure 20,000 times (a "Monte Carlo" simulation [33]) to obtain a distribution of the estimated cost-effectiveness ratios.

Ranges (upper and lower bounds) of all of the parameters (except condom use, condom effectiveness, and the number of QALYs saved per HIV case averted) were chosen as $\pm 50 \%$ of the parameter's base case value to allow for a wide variance in the values we applied in our sensitivity analyses. The selection of ranges for condom usage among intervention participants is described in the appendix. An analysis of HIV seroconversion studies indicated that condom usage decrease the per-act risk of HIV infection by $90 \%$ to $95 \%$ [25]. We applied a slightly wider range ( $85 \%$ to $98 \%$ ) of possible values for condom effectiveness. The range for the number of QALYs saved per HIV case averted was obtained from a previously published study [27].

\section{Results}

The intervention costs are summarized in Table 3. The complete intervention cost an estimated $\$ 456$ per participant, while the condom use skills component cost an estimated \$193 per participant.

Table 3: Summary of cost estimates of complete WINGS intervention, per cohort of six women

\begin{tabular}{|c|c|c|c|}
\hline Item & Cost & Description of cost calculations & Source \\
\hline Facility rent & $\$ 381$ & $\begin{array}{l}\text { I.5 months at } \$ 169 \text { per month ( } 25 \% \text { usage of } \$ 677 \text { per-month room, } \\
\text { including utilities), multiplied by } 1.5 \text { to include miscellaneous costs }\end{array}$ & survey \\
\hline Facilitator salary and benefits & $\$ 660$ & $\begin{array}{l}\$ 16 \text { per hour (including fringe benefits), } 20.5 \text { hours per facilitator per } \\
\text { cohort ( } 6 \text { sessions of } 3.4 \text { hours including } 0.9 \text { hours prep time per ses- } \\
\text { sion), two facilitators per cohort }\end{array}$ & survey, budget \\
\hline Facilitator training & $\$ 61$ & $\begin{array}{l}\text { I. } 25 \text { hours per facilitator ( } \$ 16 \text { per hour) per cohort ( } 20 \text { hours overall } \\
\text { training, divided by } 16 \text { cohorts), multiplied by } 1.5 \text { to include indirect } \\
\text { costs, two facilitators per cohort }\end{array}$ & survey, budget \\
\hline Recruitment & $\$ 208$ & $\begin{array}{l}\$ 176 \text { staff time (hours and wages varied across sites) and } \$ 32 \text { supplies } \\
\text { (flyers, ads, letters) }\end{array}$ & survey, budget \\
\hline Incentive payments & $\$ 649$ & $\$ 18$ per participant per session, 6 sessions & survey \\
\hline Client transportation/meals & $\$ 260$ & $\$ 7.23$ per participant per session, 6 sessions & survey \\
\hline $\begin{array}{l}\text { Senior staff time for quality } \\
\text { assurance }\end{array}$ & $\$ 110$ & $\$ 18$ per participant & $\begin{array}{l}\text { Holtgrave and Kelly } \\
\text { [13] }\end{array}$ \\
\hline Course materials & $\$ 159$ & $\begin{array}{l}\text { includes male and female condom models, condoms, printed materi- } \\
\text { als }\end{array}$ & $\begin{array}{l}\text { survey, advertised } \\
\text { prices }\end{array}$ \\
\hline Child care & $\$ 252$ & $\begin{array}{l}\text { Half of the women (or, } 3 \text { women per session) required } 2.5 \text { hours of } \\
\text { childcare per session, at } \$ 5.60 \text { per hour, six sessions }\end{array}$ & $\begin{array}{l}\text { Holtgrave and Kelly } \\
{[13]}\end{array}$ \\
\hline Total & $\$ 2,739$ & & \\
\hline
\end{tabular}

Notes: Costs are expressed in 1996 US\$. Based on these estimated costs per cohort of six, the cost of the complete intervention per person was $\$ 456$. The estimated cost of the condom use skills component was $\$ 1,158$ per cohort of six, or $\$ 193$ per participant. The described calculations might not exactly match the cost column due to rounding. In the source column, "survey" indicates the information was based on survey of WINGS principal investigators and "budget" indicates the information was based on budget proposals submitted by WINGS principal investigators. 
Table 4: Selected cost and effectiveness estimates

Indirect HIV costs included
Indirect HIV costs excluded

$\begin{array}{cccc}\begin{array}{c}\text { Complete } \\ \text { intervention }\end{array} & \begin{array}{c}\text { Condom use skills component } \\ \text { of intervention }\end{array} & \begin{array}{c}\text { Complete } \\ \text { intervention }\end{array} & \begin{array}{c}\text { Condom use skills component of } \\ \text { intervention }\end{array} \\ \$ 121,296 & \$ 51,338 & \$ 121,296 & \$ 51,338 \\ 0.2195 & 0.1756 & 0.2195 & 0.1756 \\ \$ 73,960 & \$ 59,168 & \$ 42,796 & \$ 34,237 \\ \$ 47,336 & -\$ 7,830 & \$ 78,500 & \$ 17,101 \\ \$ 215,690 & \text { cost-saving } & \$ 357,690 & \$ 97,404 \\ \$ 1,256,831 & - & \$ 1,398,831 & - \\ \text { na } & \text { na } & \$ 31,851 & \$ 8,674 \\ \text { na } & \text { na } & \$ 124,562 & -\end{array}$

Notes: Costs are expressed in 1996 US\$. The average cost per case averted (the average cost-effectiveness ratio) compares each option to the alternative of no intervention, which has a program cost of $\$ 0$ and results in 2.54 new HIV infections. The incremental cost-effectiveness ratios compare the complete intervention to the option of offering only the condom use skills component. "Cost-saving" indicates that the averted HIV costs exceeded the cost of the intervention. We did not calculate cost-effectiveness ratios using QALYs when indirect HIV costs were included in the analysis, as the QALY measures to some degree incorporate these indirect costs.

Table 5: Univariate sensitivity analyses: Estimated cost per HIV case averted over a range of parameter values

Indirect HIV costs included

Complete intervention Condom use skills Complete intervention component
Parameter varied

\section{Indirect HIV costs excluded}

Condom use skills component
Annual probability of acquiring HIV $=0.0095$

Annual probability of acquiring HIV $=0.029$

Condom use $=55.45 \%$ (55\% for condom use skills component)

Condom use $=59.95 \%$ ( $58.6 \%$ for condom use skills component)

Duration of intervention effect (months) $=3$

Duration of intervention effect (months) $=9$

Condom effectiveness $=85 \%$

Condom effectiveness $=98 \%$

Intervention cost $=\$ 228$ ( $\$ 97$ for condom use skills component)

Intervention cost $=\$ 684$ ( $\$ 290$ for condoms use skills component)

Cost per case of HIV $=\$ 169,000$ ( $\$ 98,000$ excluding indirect costs)

Cost per case of HIV $=\$ 506,000$ ( $\$ 293,000$ excluding indirect costs)

$\$ 771,037$
$\$ 24,186$
$\$ 768,380$

$\$ 31,460$

$\$ 765,735$
$\$ 32,343$
$\$ 347,154$
$\$ 181,482$
cost-saving

$\$ 492,035$

$\$ 383,690$

$\$ 46,690$

$\begin{array}{cc}\$ 249,215 & \$ 913,037 \\ \text { cost-saving } & \$ 166,186 \\ \$ 247,809 & \$ 910,380 \\ & \\ \text { cost-saving } & \$ 173,460 \\ & \\ \$ 246,410 & \$ 907,735 \\ \text { cost-saving } & \$ 174,343 \\ \$ 24,957 & \$ 489,154 \\ \text { cost-saving } & \$ 323,482 \\ \text { cost-saving } & \$ 81,345 \\ \$ 102,364 & \$ 634,035 \\ \$ 123,404 & \$ 454,690 \\ \text { cost-saving } & \$ 259,690\end{array}$

$\$ 391,215$

cost-saving

$\$ 389,809$

cost-saving

$\$ 388,410$

$\$ 403$

$\$ 166,957$

$\$ 79,307$

cost-saving

$\$ 244,364$

$\$ 194,404$

cost-saving

Note: Costs are expressed in 1996 US\$. "Cost-saving" indicates that the averted HIV costs exceeded the cost of the intervention. 
Table 6: Multivariate sensitivity analyses: Estimated cost per case of HIV averted when varying all parameters simultaneously

\begin{tabular}{|c|c|c|c|c|}
\hline & \multicolumn{2}{|c|}{ Indirect HIV costs included } & \multicolumn{2}{|c|}{ Indirect HIV costs excluded } \\
\hline & Complete intervention & Condom use skills component & Complete intervention & Condom use skills component \\
\hline Median & $\$ 302,254$ & $\$ 13,504$ & $\$ 444,409$ & $\$ 150,201$ \\
\hline Lower bound & cost-saving & cost-saving & $\$ 27,506$ & cost-saving \\
\hline Upper bound & $\$ 1,522,430$ & $\$ 660,175$ & $\$ 1,635,740$ & $\$ 783,820$ \\
\hline
\end{tabular}

Note: Costs are expressed in 1996 US\$. "Cost-saving" indicates that the averted HIV costs exceeded the cost of the intervention. The lower and upper bound values in the multivariate sensitivity analysis represent the $5^{\text {th }}$ and $95^{\text {th }}$ percentiles, respectively, of the cost-effectiveness ratios generated in the Monte Carlo estimations.

The complete intervention averted an estimated 0.2195 new infections (Table 4 ) at a cost of $\$ 215,690$ per case averted, while the condom use skills component averted an estimated 0.1756 and was cost-saving. Compared to the condom use skills component, the incremental costeffectiveness ratio of the complete intervention was more than $\$ 1$ million per case averted.

When we excluded the indirect costs of HIV, the cost per case averted was $\$ 357,690$ for the complete intervention and $\$ 97,404$ for the condom use skills component. The cost per QALY saved was $\$ 31,851$ for the complete intervention and $\$ 8,674$ for the condom use skills component.

\section{Sensitivity analyses}

In the univariate sensitivity analysis (Table 5), the cost per case averted for the complete intervention ranged from cost-saving (a negative cost per case averted) to more than $\$ 750,000$. The cost per case averted for the condom use skills component ranged from cost-saving to almost $\$ 250,000$. The results were most sensitive to changes in the annual probability of acquiring HIV, the effectiveness of the intervention (as measured by condom use among intervention participants), the duration of the intervention's effect on condom usage, and the cost of the intervention. When indirect costs of HIV were excluded, the cost per case averted ranged from $\$ 81,345$ to more than $\$ 900,000$ for the complete intervention and from costsaving to almost $\$ 400,000$ for the condom use skills component.

In the multivariate sensitivity analysis (Table 6), the cost per case averted for the complete intervention ranged from cost-saving to more than $\$ 1.5$ million, with a median value of $\$ 302,254$. The cost per case averted for the condom use skills component ranged from cost-saving to more than $\$ 600,000$ per case of HIV averted, with a median value of $\$ 13,504$. When considering only the direct medical care costs of HIV, the median cost per case averted was $\$ 444,409$ (range: $\$ 27,506$ to $\$ 1.6$ million) for the complete intervention and $\$ 150,201$ (range: cost-saving to $\$ 783,820$ ) for the condom use skills component.

\section{Discussion}

This analysis supports the findings of previous studies that demonstrate that multi-session behavioural interventions in group settings can be cost-effective tools in the prevention of HIV [34]. Our analysis indicated that the complete intervention prevented an estimated 0.2195 new cases of HIV at a cost of $\$ 215,690$ per case of HIV averted. The condom use skills component prevented an estimated 0.1756 HIV infections and was cost-saving.

The cost-effectiveness ratios appear less favourable when the indirect costs of HIV are not included in the analysis. When excluding indirect costs of HIV, the cost per case of HIV averted was $\$ 357,690$ for the complete intervention and $\$ 97,404$ for the condom use skills component. The cost per QALY saved was $\$ 31,851$ for the complete intervention and $\$ 8,674$ for the condom use skills component.

To put these estimates into perspective, a recent review of HIV prevention interventions in the USA suggested that an HIV prevention intervention can be considered cost-effective if the cost per QALY saved is less than $\$ 50,000$ [34]. The base case estimates of the cost per QALY averted for the complete intervention and the condom use skills component fell below this $\$ 50,000$ threshold.

Although the WINGS intervention (particularly the condom use skills component) appeared to be cost-effective in the base case analysis, the estimated cost-effectiveness of the WINGS intervention is less favourable than that of two other small group HIV prevention programs for at risk women $[13,35]$. Furthermore, the incremental cost per QALY saved $(\$ 124,562)$ exceeded the $\$ 50,000$ threshold, suggesting that the additional benefits of the complete intervention (as compared to the condom use skills compo- 
nent) might not be worth the additional costs of the complete intervention.

\section{Improving the cost-effectiveness of HIV prevention inter- ventions}

The finding that the condom use skills component was more cost-effective than the complete intervention is consistent with previous studies demonstrating the effectiveness of brief STD/HIV counselling sessions for persons at high risk for HIV and STDs [8,36]. These findings suggest the possibility that for a given budget, more HIV infections could be prevented by providing brief interventions to a larger number of people at risk for HIV rather than providing more intensive and lengthy interventions to a smaller number of people at risk for HIV.

Our analysis also illustrated the importance of targeting the intervention to those at the highest risk for HIV. The cost-effectiveness ratios improved substantially when we assumed an annual probability of acquiring HIV of 3\% per year (Table 5), a probability consistent with HIV incidence rates in some populations of high-risk urban women [19-22].

Reductions in the cost of the intervention would improve the program's cost-effectiveness (Table 5). The WINGS intervention might be delivered in a more cost-effective manner in other settings. For example, if incorporated into existing programs such as drug treatment or into corrections settings, additional recruitment expenses, incentive payments, transportation, meals, and child care would not be required.

\section{Limitations}

Our analysis is subject to at least four main limitations, the most important of which is the uncertainty in quantifying the effectiveness of the WINGS intervention. Intervention participants showed a significant increase in use of the female condom as compared to the control group [15]. Condom usage, as measured by the odds of condom use (male and female condoms), increased substantially for women in the intervention and for women in the control group [10]. Although this increase in condom usage for women in the intervention was not statistically different from the (lesser) increase shown by women in the control group, the WINGS intervention did increase condom use skills and communication skills, and these improved skills were linked to increases in the probability of condom usage [10] (see appendix).

A second limitation is that the condom use skills component was not actually offered as separate, brief intervention, but was part of the six-session intervention required of all of the WINGS participants. As a result, we based our analysis of the effectiveness of the condom use skills com- ponent and the complete intervention on estimates of the efficacy of individual components of the intervention suggested by a structural equation model of the complete intervention's efficacy (see appendix). If we incorrectly attributed some of the effect of the complete intervention to the condom use skills component, our estimates will understate the incremental cost-effectiveness of the complete intervention and overstate the average cost-effectiveness of the condom use skills component. Further, because the effects of the condom use skills component may be different when provided alone than when provided in the context of a longer, multifaceted intervention, the estimated cost-effectiveness of the condom use skills component may be biased.

A third limitation is the uncertainty in estimating the number of HIV infections averted by the increase in condom use. Our simple approximation was based on an application [18] of a Bernoulli model of HIV transmission which found that the relationship between increased condom usage and HIV risk reduction is essentially linear for most heterosexuals at risk for HIV.

In our simplified model we applied the estimated annual probability of acquiring HIV among high-risk urban women. This average annual probability reflects an average of the various epidemiological and behavioural factors which affect the annual probability of acquiring HIV, such as per-act HIV transmission probabilities, number of sex partners, and HIV prevalence rates in the sex partners. The annual probability of acquiring HIV was the only key input required for our model to provide an estimate of the number of HIV cases averted through an increase in condom usage. Precise values for annual probability of acquiring HIV were difficult to obtain. Our base case probability of acquiring HIV for the WINGSparticipants (0.019) was higher than suggested by the incidence rates reported in some studies of women at high risk for acquiring HIV ( 0.018 to 1.2 new infections per 100 person-years $[23,24])$, but substantially lower than others (3 or more new infections per 100 person-years [19-22]).

A fourth limitation is that we collected cost information retrospectively from the WINGS intervention principal investigators. The cost estimates they provided, however, were reasonably consistent with the detailed budget proposals they submitted prior to the delivery of the intervention. Furthermore, the estimated cost of the WINGS intervention ( $\$ 456$ per participant) is consistent with that of other small-group HIV prevention interventions for women ( $\$ 450$ per participant in a seven-session intervention [35] and $\$ 300$ per participant in a five-session intervention [13]). 


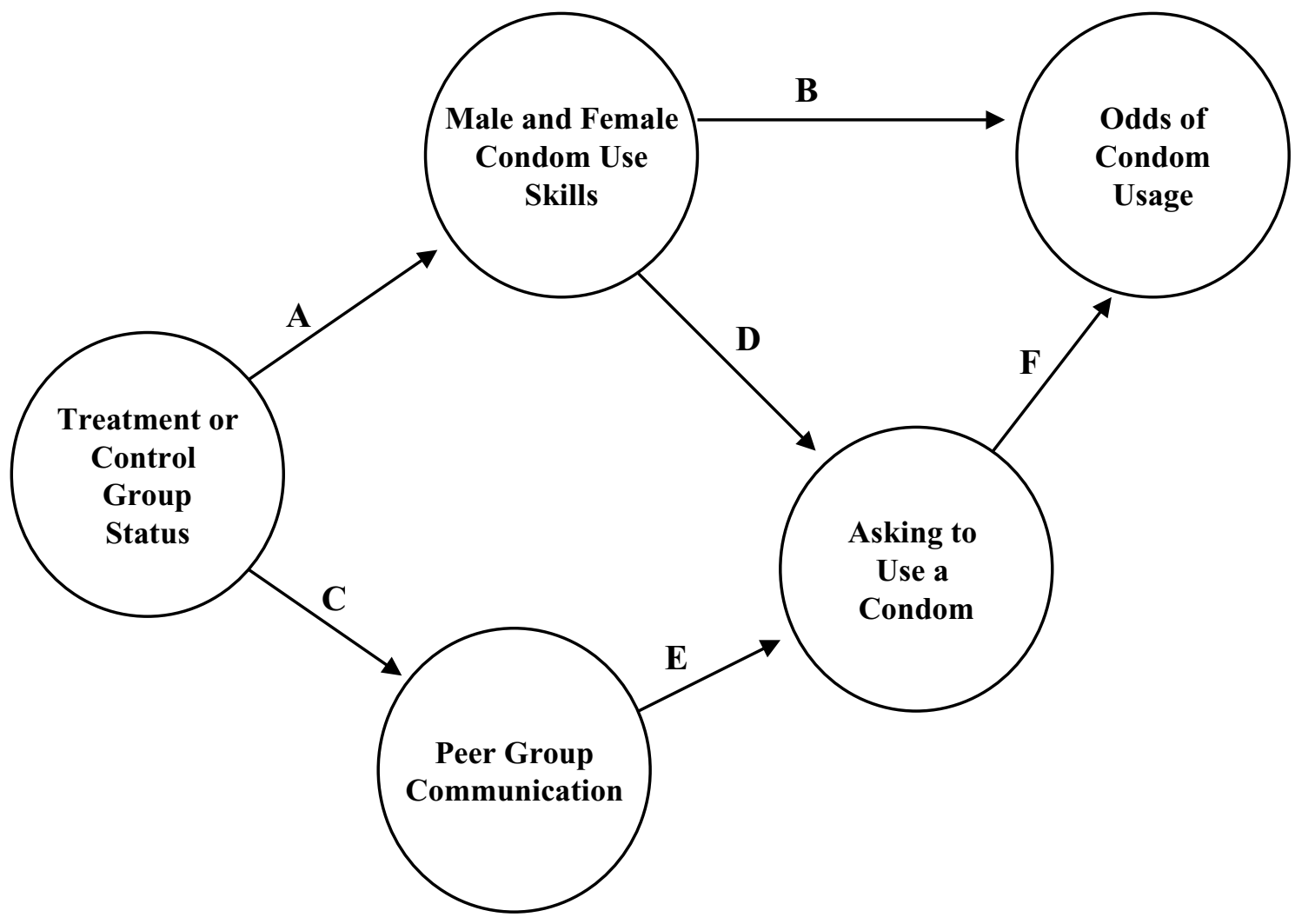

Figure I

Simplified version of structural equation model used to evaluate the effectiveness of the WINGS intervention. The regression coefficient linking the Treatment or Control Group Status variable and the Odds of Condom Usage is $\left(A^{*} B\right)+\left(C^{*} E^{*} F\right)+$ $(A * D * F)$, where $A, B, C, D, E$, and $F$ were obtained from Greenberg et al., 2000 [10].

\section{Potential underestimation of cost-effectiveness}

Unlike the WINGS intervention, many HIV interventions have been found to be cost-saving $[7,34]$, which occurs when the costs of HIV averted by the intervention outweighs the cost of implementing the intervention. We note that the condom skills component of the intervention, however, did appear to be cost-saving when indirect costs of HIV were included in the analysis. Under many scenarios explored in the sensitivity analyses the WINGS intervention and the condom use skills component were cost-saving.

Furthermore, additional limitations of our analysis may have caused a substantial underestimation of the cost-effectiveness of the WINGS intervention. First, our analysis focussed on the prevention of the acquisition of HIV among women in the intervention and ignored the possibility of preventing HIV infection among the women's sex partners. Second, in focussing only on HIV prevention we ignored other potential benefits of the intervention such as reductions in STDs and unintended pregnancies.

Third, although the intervention participants reported a substantial increase in condom usage, we only attributed a small part of this increase to the effects of the intervention. The increase in condom usage we did attribute to the intervention was the increase above and beyond the increase in condom usage reported by the control group, and it is possible that part of the increase in condom usage by the control group was attributable to participation in the WINGS trial. For example, measures of condom use skills were obtained for women in the control group on several occasions, requiring the women to perform such tasks as opening the condom package, unrolling the condom, and placing the condom on an anatomical model. If participation in these tasks contributed to the increase in 
condom usage by the women in the control group, then the actual effectiveness of the WINGS intervention would be understated in our analysis.

\section{Conclusions}

In sum, both the complete intervention and the two-session condom use skills component appeared to be at least moderately cost-effective in preventing HIV among at-risk urban women, using published cost-effectiveness standards for HIV prevention interventions. Our analysis indicated that group interventions consisting of two sessions may be more cost-effective than six sessions and suggested that, for a given HIV prevention budget, offering brief interventions for a large number of at-risk women may be more cost-effective in some cases than longer, more intensive and multifaceted interventions for a smaller number of at-risk women.

\section{Appendix}

The efficacy of the WINGS intervention was based on a previously published evaluation which used a structural equation model [10]. To estimate $\rho_{\mathrm{b}}$, the probability of condom use without the intervention, we used the probability of condom use for the control group. At three month followup, the (log) odds ratio of protected sex in the control group was 0.13 . Thus, $\log \left(\rho_{\mathrm{b}} / 1-\rho_{\mathrm{b}}\right)=.13$, or $\rho_{\mathrm{b}} /\left(1-\rho_{\mathrm{b}}\right)=1.1388$, or $\rho_{\mathrm{b}}=0.5324$.

To estimate $\rho_{\mathrm{i}}$, the probability of condom use with the intervention, we estimated the increase in condom usage associated with the intervention. The structural equation model estimates suggested that the intervention increased the log (odds) of condom use by 0.1818 .

This value was estimated as the appropriate product of the unstandardized path coefficients connecting the intervention variable to the odds ratio of condom use outcome. A simplified version of the model at 3 months after the intervention is provided in Figure 1.

Through recursive substitutions [37], it can be shown that the regression coefficient linking the Treatment or Control Group Status variable and the Odds of Condom Usage is: $\left(A^{*} B\right)+\left(C^{*} E^{*} F\right)+\left(A^{*} D^{*} F\right)$, where $A, B, C, D, E$, and $F$ are all coefficients to be estimated. Applying the published estimates (Table 3 in Greenberg et al. 2000 [10]) of these coefficients yielded an estimated 0.1818 increase in the $(\log )$ odds of condom usage attributable to the intervention. Thus, for the complete intervention, $\log \left(\rho_{\mathrm{i}} / 1-\rho_{\mathrm{i}}\right)$ $=0.13+0.1818$, or $\rho_{\mathrm{i}} /\left(1-\rho_{\mathrm{i}}\right)=1.3659$, or $\rho_{\mathrm{i}}=0.5773$.

Similarly, we calculated the effect of increased condom use skills by calculating $\left(A^{*} B\right)+\left(A^{*} D^{*} F\right)$, which yielded an estimated 0.1436 increase in the log (odds) of condom usage attributable to the condom use skills component.
Thus, for the condom use skills component, $\log \left(\rho_{\mathrm{i}} / 1\right.$ $\left.\rho_{\mathrm{i}}\right)=0.13+0.1436$, or $\rho_{\mathrm{i}} /\left(1-\rho_{\mathrm{i}}\right)=1.3147$, or $\rho_{\mathrm{i}}=0.5680$.

In sum, the estimated probability of condom usage for a given act of sexual intercourse is $53.2 \%$ without the intervention, $57.7 \%$ for the complete intervention and $56.8 \%$ for the condom use skills component. Using these baseline probabilities, condom usage is increased by 4.5 percentage points (in absolute terms) among women in the complete intervention, of which 3.6 percentage points could be attributed to the condom use skills component. To generate ranges (to be used in the sensitivity analysis) for the estimated condom usage among intervention participants, we varied these increases by $\pm 50 \%$.

\section{Competing interests}

None declared.

\section{Authors' contributions}

HWC conducted the cost and cost-effectiveness analyses and drafted the manuscript. JBG initiated the study and contributed to the cost and cost-effectiveness analyses. $\mathrm{MH}$ contributed to the cost-effectiveness analysis and drafted the appendix. All authors contributed to the writing and reviewing of the manuscript and have read and approved the final version.

\section{Acknowledgements}

We thank the following WINGS principal investigators for their assistance in our cost analysis: David Celentano, ScD, The Johns Hopkins University; Ann Downer, EdD, and Virginia Gonzales, EdD, University of Washington, Seattle; and Nancy Van Devanter, DrPH, Columbia University. We also thank Kathleen Irwin, MD, Centers for Disease Control and Prevention, for helpful comments and suggestions.

\section{References}

I. Centers for Disease Control and Prevention: HIVIAIDS among US women: Minority and young women at continuing risk. Atlanta: Centers for Disease Control and Prevention 2000

2. Exner TM, Seal DW, Ehrhardt AA: A review of HIV interventions for at-risk women. AIDS Behav 1997, I:93-124

3. Kelly JA, St Lawrence JS, Hood HV, Brasfield TL: Behavioral intervention to reduce AIDS risk activities. J Consult Clin Psychol I989, 57:60-67

4. Hobfoll SE, Jackson AP, Lavin J, Britton PJ, Shepherd JB: Reducing inner-city women's AIDS risk activities: a study of single, pregnant women. Health Psychol 1994, 13:397-403

5. Kelly JA, Murphy DA, Washington CD, Wilson TS, Koob JJ, Davis DR, et al: The effects of HIVIAIDS intervention groups for highrisk women in urban clinics. Am J Public Health 1994, 84:19181922

6. DiClemente RJ, Wingood GM: A randomized controlled trial of an HIV sexual risk-reduction intervention for young AfricanAmerican women. JAMA 1995, 274: I27I-I 276

7. Holtgrave DR, Qualls NL, Curran JW, Valdiserri RO, Guinan ME, Parra WC: An overview of the effectiveness and efficiency of HIV preventionprograms. Public Health Rep 1995, I I 0:134-146

8. Branson BM, Peterman TA, Cannon RO, Ransom R, Zaidi AA: Group counseling to prevent sexually transmitted disease and HIV: a randomized controlled trial. Sex Transm Dis 1998, 25:553-560

9. Celentano DD, Dilorio C, Hartwell T, Kelly J, Magana R, Maibach E, et al: The NIMH multisite HIV prevention trial: Reducing HIV sexual risk behavior. Science 1998, 280: 1889-1894

10. Greenberg J, Hennessy M, MacGowan R, Celentano D, Gonzales V, Van Devanter $N$, et al: Modeling intervention efficacy for high- 
risk women - The WINGS Project. Eval Health Prof 2000, 23: $123-148$

1I. Cohen D, Dent C, MacKinnon D: Condom skills education and sexually transmitted disease reinfection. J Sex Res I99I, 28:139-144

12. Cohen DA, Mackinnon DP, Dent C, Mason HR, Sullivan E: Group counselling at STD clinics to promote use of condoms. Public Health Rep 1992, 107:727-731

13. Holtgrave DR, Kelly JA: Preventing HIVIAIDS among high-risk urban women: the cost-effectiveness of a behavioral group intervention. Am J Public Health 1996, 86: I 442-I 445

14. Greenberg J, Lifshay J, Van Devanter N, Gonzales V, Celentano D: Preventing HIV infection: The effects of community linkages, time, and money on recruiting and retaining women in intervention groups. J Womens Health 1998, 7:587-596

15. Van Devanter N, Gonzales V, Merzel C, Parikh NS, Celantano D, Greenberg ]: Effect of an STD/HIV behavioral intervention on women's use of the female condom. Am J Public Health 2002 92:109-115

16. Fisher JD, Fisher WA: Changing AIDS-risk behavior. Psychol Bull 1992, I I I:455-474

17. Farnham PG, Ackerman SP, Haddix AC: Study design. In Prevention effectiveness: A guide to decision analysis and economic evaluation (Edited by: Haddix AC, Teutsch SM, Shaffer PA, Duñet DO) New York, Oxford University Press 1996, 12-26

18. Pinkerton SD, Abramson PR: Occasional condom use and HIV risk reduction. J Acquir Immune Defic Syndr Hum Retrovirol 1996, 13:456-460

19. Otten MW Jr, Zaidi AA, Peterman TA, Rolfs RT, Witte JJ: High rate of HIV seroconversion among patients attending urban sexually transmitted disease clinics. AIDS 1994, 8:549-553

20. Edlin BR, Word CO, McCoy CB, Faruque S, Dushku JC, Holmberg SD: HIV incidence among young urban street-recruited crack cocaine smokers. Natl Conf Hum Retroviruses Relat Infect (2nd) 1995

21. Onorato IM, Klaskala W, Morgan WM, Withum D: Prevalence, incidence, and risks for HIV-I infection in female sex workers in Miami, Florida. J Acquir Immune Defic Syndr Hum Retrovirol 1995, 9:395-400

22. Peterman TA, Zaidi AA, Wroten J: Decreasing prevalence hides a high HIV incidence: Miami. AIDS 1995, 9:965-970

23. Weinstock H, Sweeney S, Satten GA, Gwinn M: HIV seroincidence and risk factors among patients repeatedly tested for HIV attending sexually transmitted disease clinics in the United States, I99I to 1996. STD clinic HIV seroincidence study group. J Acquir Immune Defic Syndr Hum Retrovirol 1998, 19:506-5I 2

24. Chirgwin KD, Feldman J, Dehovitz JA, Minkoff H, Landesman SH: Incidence and risk factors for heterosexually acquired HIV in an inner-city cohort of women: temporal association with pregnancy. J Acquir Immune Defic Syndr Hum Retrovirol 1999, 20:295 299

25. Pinkerton SD, Abramson PR: Effectiveness of condoms in preventing HIV transmission. Soc Sci Med 1997, 44:1303-1312

26. Haddix AC, Shaffer PA: Cost-effectiveness analysis. In Prevention Effectiveness: A guide to decision analysis and economic evaluation. (Edited by: Haddix AC, Teutsch SM, Shaffer PA, Duñet DO) New York, Oxford University Press 1996, 12-26

27. Holtgrave DR, Pinkerton SD: Updates of cost of illness and quality of life estimates for use in economic evaluations of HIV prevention programs. J Acquir Immune Defic Syndr Hum Retrovirol 1997, 16:54-62

28. Mullins CD, Whitelaw G, Cooke IL, Beck El: Indirect cost of HIV infection in England. Clin Ther 2000, 22:1333-1345

29. McKay NL, Phillips KM: An economic evaluation of mandatory premarital testing for HIV. Inquiry I99I, 28:236-248

30. Holtgrave DR, Valdiserri RO, Gerber AR, Hinman AR: Human immunodeficiency virus counseling, testing, referral, and partner notification services. A cost-benefit analysis. Arch Intern Med 1993, 153:1225-1230

31. Prevention effectiveness: A guide to decision analysis and economic evaluation. (Edited by: Haddix AC, Teutsch SM, Shaffer PA, Duñet DO) New York, Oxford University Press 1996, I2-26

32. Cost-effectiveness in health and medicine. (Edited by: Gold $M R$, Siegel JE, Russell LB, Weinstein MC) New York, Oxford University Press 1996
33. Doubilet P, Begg CB, Weinstein MC, Braun P, McNeil B]: Probabilistic sensitivity analysis using Monte Carlo simulation. A practical approach. Med Decis Making 1985, 5:157-177

34. Pinkerton SD, Johnson-Masotti AP, Holtgrave DR, Farnham PG: Using cost-effectiveness league tables to compare interventions to prevent sexual transmission of HIV. AIDS 200I, 15:917-928

35. Pinkerton SD, Holtgrave DR, Johnson-Masotti AP, Turk ME, Hack KL, DiFranceisco W, et al: Cost-effectiveness of the NIMH multisite HIV prevention intervention. AIDS Behav 2002, 6:83-96

36. Kamb ML, Fishbein M, Douglas JMJ, Rhodes F, Rogers J, Bolan G, et al: Efficacy of risk-reduction counseling to prevent human immunodeficiency virus and sexually transmitted diseases: a randomized controlled trial. Project RESPECT Study Group. JAMA 1998, 280: | |61-1|67

37. Short L, Hennessy M: Using structural equations to estimate the effects of behavioral interventions. Struct Equation Mode $|994| 1:, 68-8 \mid$

\section{Pre-publication history}

The pre-publication history for this paper can be accessed here:

http://www.biomedcentral.com/1471-2334/2/24/prepub

Publish with BioMed Central and every scientist can read your work free of charge

"BioMedcentral will be the most significant development for disseminating the results of biomedical research in our lifetime." Paul Nurse, Director-General, Imperial Cancer Research Fund

Publish with BMC and your research papers will be:

- available free of charge to the entire biomedical community

- peer reviewed and published immediately upon acceptance

- cited in PubMed and archived on PubMed Central

- yours - you keep the copyright
BioMedcentral.com editorial@biomedcentral.com 